\title{
A STUDY ON THE EFFECTS OF AUTHENTIC LEADERSHIP ON PSYCHOLOGICAL CAPITAL AND KNOWLEDGE SHARING IN CHINA ASSOCIATION FOR NGO COOPERATION
}

\author{
Lu MINGYUAN $^{1}-\mathrm{Li} \mathrm{GENG}^{2}$ \\ ${ }^{1}$ College of Management and Economics, Tianjin University, China. \\ E-mail:lmygh002@163.com (corresponding author) \\ ${ }^{2}$ College of Management and Economics, Tianjin University, China. \\ E-mail:60216@163.com
}

Regardless of public sectors, private enterprises, or non-profit organizations, breach of good faith and violation of regulation are emerging endlessly in past years. A genuine and honest leader is a key success factor in maintaining organizational running. Authentic leadership is regarded as the foundation of business success. An authentic leader applies positive morality and has the highmorality and value behaviors and languages be the paradigm. It is considered in this study that a non-profit organization could effectively affect the first-line administrators and organizational volunteers, through a leader's authentic leadership style, transform the degree of psychological capital and knowledge sharing intention and further enhance the operating performance of the non-profit organization.

The leaders and administrators in China Association for NGO Cooperation, as the research samples, are distributed the questionnaires, and 428 valid copies are retrieved, with the retrieval rate $71 \%$. The research results are summarized as following. 1. Authentic leadership shows significant correlations with psychological capital. 2. Psychological capital reveals remarkable correlations with knowledge sharing. 3. Authentic leadership presents notable correlations with knowledge sharing. 4. Psychological capital appears mediating effects on the relation between authentic leadership and knowledge sharing. This study intends to discuss whether authentic leaders in non-profit organizations could enhance the employees willing to actively share knowledge through psychological capital, provide reference opinions for the practical operation of non-profit organizations, and propose suggestions for possible directions.

Keywords: non-profit organization, authentic leadership, psychological capital, knowledge sharing 


\section{RESEARCH BACKGROUND}

Genuineness, as a virtue, is the innate nature, from the aspect of human goodness by nature, and external incentives would make people gradually lose the hearts and courage to keep the genuineness. Various vicious tactics have distanced people to the vicious circle. The public therefore is disappointed, panic, and not believing in others. People's integrity and good faith are highly praised social values in both eastern and western societies. Regardless of public sectors, private enterprises, or non-profit organization, breach of good faith and even violation of regulation emerge endlessly in past years; the burst scandals not only result in large amount of loss and waste as well as distortion and deviation of people value, but also cause profound negative effects on the entire social atmosphere. Genuineness should be regarded as a universal value which people should obey anywhere anytime. Education presents the sacred task of succession of generations, while genuineness reveals better importance. Human beings are compound animals who could not isolate from groups but accomplish great things by solidarity. How to have people regain the virtue of genuineness and guide organizational members to cooperate with each other is a critical issue for leaders.

The management in a non-profit organization is recently introduced the management practice and leadership theory from successful enterprises because of the effects of business organizations. An authentic leader is the key success factor in maintaining organizational running, and authentic leadership is the foundation of business success. Authentic leadership refers to the leader personally treating each employee and everything consistently and with genuineness and affecting each employee with genuineness to engage in the organization. Social environments getting complicated and resulting in conflict as well as increasing pressure on non-profit organizational administrators affect the administrators' attitudes towards the work and further reduce the intention to become non-profit organizational volunteers. Authentic leaders would apply positive morality to guide and present high-morality and value behaviors and languages to be the paradigm. It is indicated in this study that a non-profit organization could effectively affect the first-line administrators and organizational volunteers through a leader's authentic leadership style to transform the psychological capital and knowledge sharing intention and further promote the operating performance of the non-profit organization. Consequently, this study expects to discuss whether non-profit organizational authentic leaders could, through psychological capital, affect employee intention to actively share knowledge, provide non-profit organizations with reference opinions for practical operation, and propose suggestions for possible directions. 


\section{LITERATURE AND HYPOTHESIS}

\subsection{Authentic leadership}

Fu and Deshpande (2012) indicated that authentic leadership developed an important item to reflect the effects on working members. The theory of authentic leadership stressed on activeness and developed the mutual function between leaders and the followers so as to be consistent with positive organizational behaviors (POB) (Luthans et al. 2010). Fu and Deshpande (2012) proposed that presenting self-awareness and self-regulation were the key factor in a leader being regarded as genuine. Researchers (Avey et al. 2010) emphasized the definition of authentic leadership being surrounded by positive psychological capital, including belief, hope, optimism, and toughness. Referring to the authentic leadership scale, developed by Fu and Deshpande (2012), which includes the dimensions of self-perception, relation transparency, equalization treatment, and internalization of morality, is a multi-dimensional authentic leadership measuring tool in this study.

(1) Self-perception. An individual perceiving and believing in personal motivation, feeling, desire, and self-related cognition, containing understanding personal advantages and drawbacks, characters, and emotion (Yildirm and Bastug 2010).

(2) Relation transparency. Referring to allowing others with frequent interaction seeing real ego, regardless of good or bad, covering the self-disclosure process and the cultivation of close relationship and trust, i.e. being honest, rather than false, to get along with others.

(3) Equalization treatment. To objectively accept individual positive and negative characteristics and quality, and deal with self-related information without bias. Related data should be objectively collected and analyzed before making decisions.

(4) Internalization of morality: $\mathrm{Fu}$ and Deshpande (2012) pointed out genuine behaviors as behaviors being consistent with authentic ego. Genuineness does not force to be a real self, but to present personal feeling, motivation, and intention under free and natural situations.

\subsection{Psychological capital}

Luthans et al. (2010) defined psychological capital as the core psychological factor in general activeness, which exceeded human capital and social capital intelligence and could have an individual acquire competitive advantages through directed investment and development (Deshpande et al. 2011). Specifically 
speaking, psychological capital was a higher-level core concept; when the four elements of self-efficacy, hope, optimism, and regeneration capacity were constructed and combined to strengthen each other, the state characteristics and the employees could be developed and managed to make the best performance and sense of satisfaction of individuals and employees so as to enhance the performance of the entire organization and employees (Fu et al. 2011). Human capital was the knowledge and skills accumulated by individual work experiences; social capital was the resource network established through individual work; and psychological capital was intrinsic psychological resources beyond human capital and social capital. Systematic investment and development allow such an active psychological state becoming a beneficial condition to enhance competitive advantages (Homburg et al. 2011).

Mayer et al. (2010) regarded psychological capital as to realize self-innermost, i.e. who you are. Psychological capital covering the following dimensions is utilized for this study.

(1) Self-efficacy. Also, named self-confidence, i.e. being confident to engage in necessary efforts and successfully complete tasks when encountering challenges.

(2) Hope. To keep positive attribution of present and future success, through incentive thinking and path thinking, and to stress on the active psychological state of an individual being able to practice the objectives through the willpower of incentive thinking and the practice ability of path thinking.

(3) Optimism. To insist on the objectives and change the approaches when necessary to acquire the success. It emphasizes that an individual would attribute positive events to intrinsic, permanent, and general factors but attribute negative ones to extrinsic, temporary, and specific factors (Yilmaz 2010).

(4) Restoring force: also called toughness. Referring to an individual being able to succeed by insisting, bearing bounce, and even exceeding when encountering dilemmas, i.e. individual good adaptation to major threats.

\subsection{Knowledge sharing}

Gentry et al. (2012) defined knowledge sharing as employees exchanging information and supporting tasks. Furthermore, Kalshoven et al. (2011) regarded knowledge sharing as a party willing to help others develop new capacities. Reed et al. (2011) considered knowledge sharing as a communication process, including the internalization of knowledge demanders and owners through knowledge reconstruction, e.g. reading; and the knowledge sharing process would be interfered by language, culture, time, and concept. McMurray et al. (2010) divided 
knowledge sharing into sharing personal knowledge, learning opportunity, assisting others in acquiring knowledge, and inventive learning. Walumbwa et al. (2011) pointed out knowledge sharing as a transfer behavior and a communication process. Knowledge share was the most important and difficult item for an organization promoting knowledge management. Knowledge presented exclusivity that knowledge dissemination could be effectively applied merely by public intention and ability (Walumbwa et al. 2010).

Referring to Walumbwa et al. (2011), knowledge sharing is divided into knowledge sharing intention and knowledge sharing behavior for measuring knowledge sharing. The operational definitions of sharing intention and sharing behavior, referred to Walumbwa et al. (2011), are described as below.

(1) Sharing intention: The degree of knowledge owners willing to deliver personal work experiences, skills, and ideas to others.

(2) Sharing behavior: The degree of knowledge owners willing to specifically deliver personal work experiences, skills, and ideas to others and expect others to actually apply them to the work after understanding (Yukl 2010).

\subsection{Research hypothesis}

Research on authentic leadership has largely emerged in past years, and researchers have gradually discovered that authentic leadership might be the core of the riddle (Resick et al. 2011). With the theoretical bases in past literatures, authentic leadership is considered as a factor in employees' psychological capital (Walumbwa et al. 2010). Fu and Deshpande (2012) indicated that authentic leadership would affect individual and social identity, indirectly change hope, confidence, and positive emotion, influence subordinates' attitudes (including commitment, job satisfaction, work meaning, and job engagement), and eventually change subordinates' behaviors, i.e. job performance, exceptional effort, and withdrawal behavior. Accordingly, the hypothesis is proposed based on the past research result.

H1: Authentic leadership presents significant correlations with psychological capital.

Mayer et al. (2010) also discovered that psychological capital would reduce employees' absence from duty and turnover. It is therefore considered in this study that psychological capital could guide employees to face the job with positive attitudes, as psychological capital could be used for forecasting the potential value of employee attitudes (Avey et al. 2010). A positive attitude could result in employees presenting positive behaviors or thoughts to face affairs and fur- 
ther make more profits for the organization, e.g. knowledge sharing. Moreover, the higher employees' psychological capital would affect their attitudes towards knowledge sharing to further show the intention to sharing personal knowledge in the organization (Homburg et al. 2011). Based on above literatures, Gentry et al. (2012) considered that a person with better confidence in the ability would reveal positive and optimistic expectation on future development and was more easily and rapidly recover after facing frustration; the person therefore would be more willing to share knowledge with others. The following hypothesis is therefore proposed in this study.

H2: Psychological capital reveals remarkable correlations with knowledge sharing.

Leadership, as the interpersonal interaction, would affect the behaviors of a person or a group of people under specific situations to achieve certain group objectives (Walumbwa et al. 2010). Past research proved the primary effects of authentic leadership on employees' knowledge sharing intention. For instance, Reed et al. (2011) pointed out the role of authentic leaders in knowledge management as Architect or Catalyst that authentic leader role and style were the factors in promoting organizational knowledge sharing. Walumbwa et al. (2011) indicated that leaders should develop the members to trust the working environment so as to be willing to share knowledge because of trust. McMurray et al. (2010) pointed out the direct effects of transformational leadership and trust on knowledge sharing intention. Kalshoven et al. (2011) found out the mediating effect of trust in management echelon on positive psychological capital and performance and the partially mediating effects on the relation between authentic leadership and knowledge sharing. Being a kind of leadership style, a lot of literatures proved the effects of leadership on knowledge sharing. Accordingly, the following hypotheses are inferred in this study.

H3: Authentic leadership shows notable correlations with knowledge sharing. H4: Psychological capital has mediating effects on the relations between authentic leadership and knowledge sharing.

\section{CONCEPTUAL FRAMEWORK AND RESEARCH METHOD DESIGN}

\subsection{Conceptual framework in this study}

Summing up the above literatures, the conceptual framework (Figure 1) is drawn in this study to investigate the relations among authentic leadership, psychological capital, and knowledge sharing. 


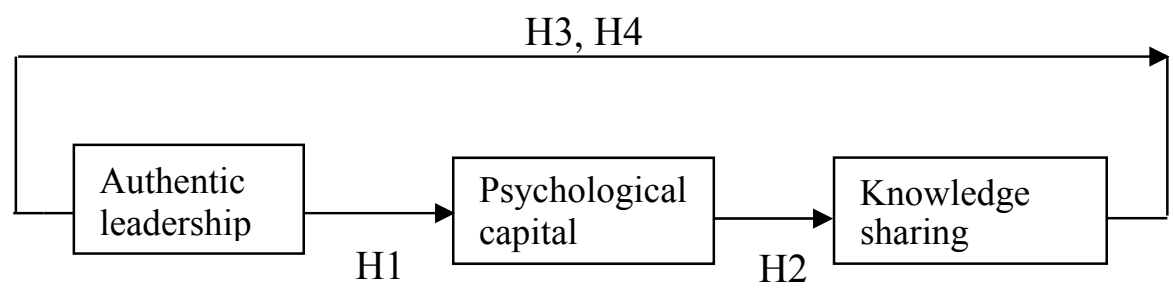

\subsection{Research subject}

Figure 1. Conceptual framework

The leaders and administrators in China Association for NGO Cooperation, as the research subjects, are distributed 600 copies of questionnaires. Deducting invalid and incomplete ones, 428 valid copies are retrieved, with the retrieval rate $71 \%$. China Association for NGO Cooperation was formally established in 1992 with the approval of the Ministry of Foreign Trade and Economic Cooperation (currently renamed Ministry of Commerce) and formally registered in the Ministry of Civil Affairs in 1993. Being a national, non-profit, united, and voluntary independent corporation, China Association for NGO Cooperation contains 142 domestic members. China Association for NGO Cooperation presents the non-governmental organization special consultative status of United Nations Economic and Social Council and is selected as the national advanced social organization by the Ministry of Civil Affairs. The future development covers to enhance the development of civil societies and to provide an exchange, communication, and support platform for civil society organizations, especially basic ones in China. China Association for NGO Cooperation therefore pays attention to poverty alleviation and development in western areas, environmental protection, and ability construction, devotes to broaden the exchange and cooperation channels among domestic government, enterprises, and research sectors, and focuses more on economic and social balance development.

\subsection{Analysis}

Regression Analysis is applied to understand the relations among authentic leadership, psychological capital, and knowledge sharing in this study. 


\section{ANALYSIS AND DISCUSSION}

\subsection{Factor Analysis of authentic leadership}

With Factor Analysis, four factors were extracted from the authentic leadership scale, including Self-perception (eigenvalue $=2.876, \alpha=0.82$ ), Relation Transparency (eigenvalue $=2.271, \alpha=0.87$ ), Equalization Treatment (eigenvalue $=$ $1.813, \alpha=0.84$ ), and Internalization of Morality (eigenvalue $=1.621, \alpha=0.86$ ). The covariance explained achieved $77.635 \%$.

With Factor Analysis, four factors were extracted from the psychological capital scale, containing Self-efficacy (eigenvalue $=3.463, \alpha=0.81$ ), Hope (eigenvalue $=2.577, \alpha=0.80$ ), Optimism (eigenvalue $=2.084, \alpha=0.89$ ), and Restoring Force (eigenvalue $=1.392, \alpha=0.83$ ). The covariance explained reached $82.761 \%$.

Two factors were extracted, with Factor Analysis, from the knowledge sharing scale, covering Sharing Intention (eigenvalue $=2.237, \alpha=0.90$ ) and Sharing behavior (eigenvalue $=1.735, \alpha=0.92$ ). The covariance explained achieved $85.341 \%$.

\subsection{Correlation Analysis of authentic leadership and psychological capital}

Applying Multiple Regression Analysis to test the hypothesis and theoretical framework, the first regression, Table 1, showed the regression equation reaching the significance $(\mathrm{F}=13.562, \mathrm{p}<0.001)$. Authentic leadership presented remarkable effects on self-efficacy, where Self-perception, Relation Transparency, Equalization Treatment, and Internalization of Morality in authentic leadership revealed notably positive effects on self-efficacy in psychological capital $(\mathrm{B}=1.633, \mathrm{p}=0.036 ; \mathrm{B}=1.597, \mathrm{p}=0.044 ; \mathrm{B}=1.746, \mathrm{p}=0.025 ; \mathrm{B}=1.832$, $\mathrm{p}=0.016)$.

The second regression, Table 1, presented the regression equation reaching the significance $(\mathrm{F}=17.416, \mathrm{p}<0.001)$. Authentic leadership appeared significant effects on hope, where Self-perception, Relation Transparency, Equalization Treatment, and Internalization of Morality in authentic leadership showed remarkably positive effects on hope in $(\mathrm{B}=1.766, \mathrm{p}=0.022 ; \mathrm{B}=1.684, \mathrm{p}=0.030$; $\mathrm{B}=2.037, \mathrm{p}=0.002 ; \mathrm{B}=1.942, \mathrm{p}=0.011$ ).

The third regression, Table 1, revealed the regression equation achieving the significance $(F=21.753, p<0.001)$. Authentic leadership appeared notable effects on optimism, where Self-perception, Relation Transparency, Equalization Treatment, and Internalization of Morality presented significantly positive effects 
on optimism in psychological capital $(\mathrm{B}=1.733, \mathrm{p}=0.024 ; \mathrm{B}=1.641, \mathrm{p}=0.032$; $\mathrm{B}=2.167, \mathrm{p}=0.000 ; \mathrm{B}=2.238, \mathrm{p}=0.000)$.

The fourth regression, Table 1, showed the regression equation reaching the significance $(\mathrm{F}=26.934, \mathrm{p}<0.001)$. Authentic leadership revealed remarkable effects on restoring force, where Self-perception, Relation Transparency, Equalization Treatment, and Internalization of Morality appeared notably positive effects on restoring force in psychological capital $(\mathrm{B}=1.825, \mathrm{p}=0.019 ; \mathrm{B}=1.967, \mathrm{p}=$ $0.009 ; \mathrm{B}=2.436, \mathrm{p}=0.000 ; \mathrm{B}=1.781, \mathrm{p}=0.020$ ). H1 therefore is supported.

Table 1. Regression Analysis of authentic leadership and psychological capital

\begin{tabular}{|c|c|c|c|c|c|c|c|c|}
\hline \multirow{3}{*}{$\begin{array}{l}\begin{array}{l}\text { Dependent } \\
\text { variable } \rightarrow\end{array} \\
\text { Independent } \\
\text { variable } \downarrow \\
\text { Authentic } \\
\text { leadership }\end{array}$} & \multicolumn{8}{|c|}{ Psychological capital } \\
\hline & \multicolumn{2}{|c|}{ Self-efficacy } & \multicolumn{2}{|c|}{ Hope } & \multicolumn{2}{|c|}{ Optimism } & \multicolumn{2}{|c|}{ Restoring force } \\
\hline & $\beta$ & $\rho$ & $\beta$ & $\rho$ & $\beta$ & $\rho$ & $\beta$ & $\rho$ \\
\hline Self-perception & $1.633^{*}$ & 0.036 & $1.766^{*}$ & 0.022 & $1.733^{*}$ & 0.024 & $1.825 *$ & 0.019 \\
\hline $\begin{array}{l}\text { Relation } \\
\text { transparency }\end{array}$ & $1.597 *$ & 0.044 & $1.684^{*}$ & 0.030 & $1.641 *$ & 0.032 & $1.967^{*}$ & 0.009 \\
\hline $\begin{array}{l}\begin{array}{l}\text { Equalization } \\
\text { treatment }\end{array} \\
\end{array}$ & $1.746^{*}$ & 0.025 & $2.037 * *$ & 0.002 & $2.167 * *$ & 0.000 & $2.436^{* *}$ & 0.000 \\
\hline $\begin{array}{l}\text { Internalization } \\
\text { of morality }\end{array}$ & $1.832 *$ & 0.016 & $1.942 *$ & 0.011 & $2.238 * *$ & 0.000 & $1.781^{*}$ & 0.020 \\
\hline $\mathrm{F}$ & \multicolumn{2}{|c|}{13.562} & \multicolumn{2}{|c|}{17.416} & \multicolumn{2}{|c|}{21.753} & \multicolumn{2}{|c|}{26.934} \\
\hline $\mathrm{P}$ & \multicolumn{2}{|c|}{$0.000 * * *$} & \multicolumn{2}{|c|}{$0.000 * * *$} & \multicolumn{2}{|c|}{$0.000 * * *$} & \multicolumn{2}{|c|}{$0.000 * * *$} \\
\hline $\mathrm{R} 2$ & \multicolumn{2}{|c|}{0.218} & \multicolumn{2}{|c|}{0.243} & \multicolumn{2}{|c|}{0.275} & \multicolumn{2}{|c|}{0.318} \\
\hline Adjusted R2 & \multicolumn{2}{|c|}{0.014} & \multicolumn{2}{|c|}{0.017} & \multicolumn{2}{|c|}{0.023} & \multicolumn{2}{|c|}{0.029} \\
\hline
\end{tabular}

Note: * stands for $\mathrm{p}<0.05, * *$ for $\mathrm{p}<0.01, * * *$ for $\mathrm{p}<0.001$.

\subsection{Correlation Analysis of authentic leadership, psychological capital and knowledge sharing}

Utilizing Multiple Regression Analysis for testing the hypothesis and theoretical framework, the first regression, Table 2, presented the regression equation reaching the significance $(\mathrm{F}=23.842, \mathrm{p}<0.001)$. Authentic leadership showed remarkable effects on knowledge sharing intention, where Self-perception, Relation Transparency, Equalization Treatment, and Internalization of Morality in authentic leadership revealed notably positive effects on knowledge sharing intention $(\mathrm{B}=1.977, \mathrm{p}=0.013 ; \mathrm{B}=2.085, \mathrm{p}=0.006 ; \mathrm{B}=2.177, \mathrm{p}=0.000$; $\mathrm{B}=2.267, \mathrm{p}=0.000$ ). The third regression, Table 2, appeared the regression equation achieving the significance $(F=32.934, p<0.001)$. Authentic leadership ap- 
peared significant effects on knowledge sharing behavior, where Self-perception, Relation Transparency, Equalization Treatment, and Internalization of Morality in authentic leadership presented remarkably positive effects on knowledge sharing behavior $(\mathrm{B}=2.152, \mathrm{p}=0.000 ; \mathrm{B}=2.133, \mathrm{p}=0.000 ; \mathrm{B}=2.279, \mathrm{p}=0.000$; $\mathrm{B}=2.312, \mathrm{p}=0.000) . \mathrm{H} 3$ is therefore supported.

The second regression, Table 2, showed the regression equation reaching the significance $(\mathrm{F}=27.551, \mathrm{p}<0.001)$. Psychological capital revealed remarkable effects on knowledge sharing intention, where Self-efficacy, Hope, Optimism, and Restoring Force in psychological capital appeared notably positive effects on knowledge sharing intention $(\mathrm{B}=2.166, \mathrm{p}=0.000 ; \mathrm{B}=2.231, \mathrm{p}=0.000$; $\mathrm{B}=2.324, \mathrm{p}=0.000 ; \mathrm{B}=2.196, \mathrm{p}=0.000$ ). The fourth regression, Table 2, presented the regression equation achieving the significance $(\mathrm{F}=35.692, \mathrm{p}<0.001)$. Psychological capital showed significant effects on knowledge sharing behavior, where Self-efficacy, Hope, Optimism, and Restoring Force in psychological capital revealed remarkably positive effects on knowledge sharing behavior $(\mathrm{B}=2.244, \mathrm{p}=0.000 ; \mathrm{B}=2.183 \mathrm{p}=0.000 ; \mathrm{B}=2.271, \mathrm{p}=0.000 ; \mathrm{B}=2.337$, $\mathrm{p}=0.000)$. H2 therefore is supported.

Table 2. Regression Analysis of authentic leadership and psychological capital

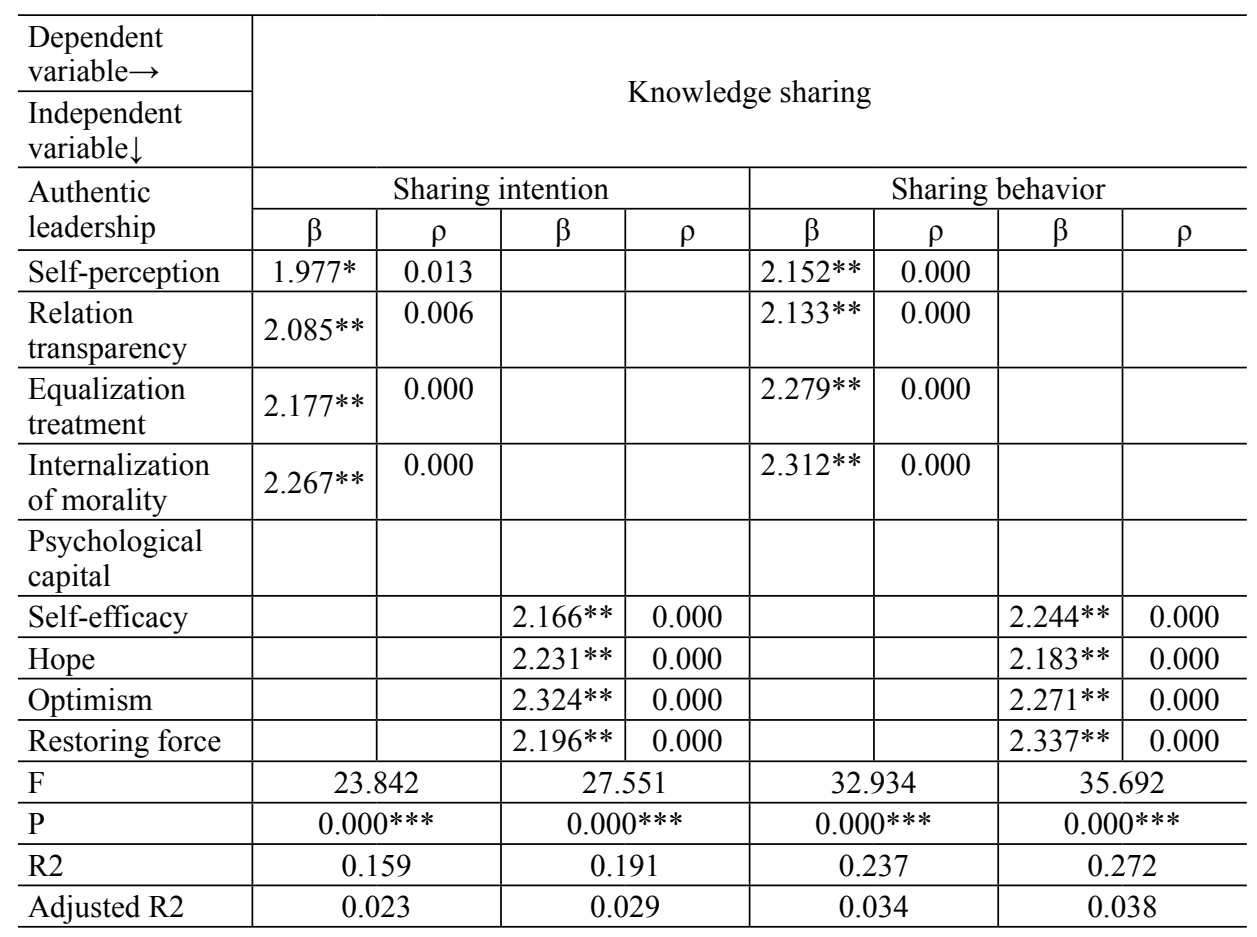

Note: $*$ stands for $\mathrm{p}<0.05, * *$ for $\mathrm{p}<0.01, * * *$ for $\mathrm{p}<0.001$. 


\subsection{Mediating effects of authentic leadership and psychological capital on knowledge sharing}

Regarding the mediating effect of psychological capital, as Hierarchical Regression Analysis in Table 3, the first regression appeared the notable explanation of authentic leadership on knowledge sharing intention $(F=23.842, p<0.001)$. According to Model II and considering the effects of authentic leadership and psychological capital on knowledge sharing intention to discuss the mediating effect of psychological capital, the $\beta$ of self-perception notably dropped from $1.977(\mathrm{p}<.05)$ down to $1.836(\mathrm{p}<.05)$, presenting that psychological capital would reduce the direct effect of self-perception on knowledge sharing intention. The $\beta$ of relation transparency significantly dropped from $2.085(\mathrm{p}<.01)$ down to $1.927(\mathrm{p}<.05)$, showing that psychological capital would reduce the direct effect of relation transparency on knowledge sharing intention. The $\beta$ of equalization treatment remarkably dropped from $2.177(\mathrm{p}<.01)$ to $1.983(\mathrm{p}<.05)$, revealing that psychological capital would reduce the direct effect of equalization treatment on knowledge sharing intention. The $\beta$ of internalization of morality notably dropped from $2.267(\mathrm{p}<.01)$ down to $2.092(\mathrm{p}<.01)$, appearing that psychological capital would reduce the direct effect of internalization of morality on knowledge sharing intention. As a result, psychological capital presented partially mediating effects on the relation between authentic leadership and knowledge sharing intention that $\mathrm{H} 4$ was supported.

In regard to the mediating effect of psychological capital, as Hierarchical Regression Analysis in Table 3, the second regression showed the remarkable explanation of authentic leadership on knowledge sharing behavior $(F=32.934$, $\mathrm{p}<0.001$ ). According to Model II and considering the effects of authentic leadership and psychological capital on knowledge sharing behavior to discuss the mediating effect of psychological capital, the $\beta$ of self-perception notably dropped from $2.152(\mathrm{p}<.01)$ to $2.032(\mathrm{p}<.01)$, revealing that psychological capital would reduce the direct effect of self-perception on knowledge sharing behavior. The $\beta$ of relation transparency notably dropped from $2.133(\mathrm{p}<.01)$ to $1.896(\mathrm{p}<.05)$, appearing that psychological capital would reduce the direct effect of relation transparency on knowledge sharing behavior. The $\beta$ of equalization treatment significantly dropped from $2.279(\mathrm{p}<.01)$ to $2.153(\mathrm{p}<.01)$, presenting that psychological capital would reduce the direct effect of equalization treatment on knowledge sharing behavior. The $\beta$ of internalization of morality remarkably dropped from $2.312(\mathrm{p}<.01)$ to $2.184(\mathrm{p}<.01)$, showing that psychological capital would reduce the direct effect of internalization of morality on knowledge sharing behavior. The research results revealed the mediating effect of psychological capital on the relations between authentic leadership and knowledge sharing behaviors that $\mathrm{H} 4$ was supported. 
Table 3. Hierarchical Regression of authentic leadership, psychological capital and knowledge sharing

\begin{tabular}{|c|c|c|c|c|c|c|c|c|}
\hline \multirow{3}{*}{$\begin{array}{l}\text { Dependent } \\
\text { variable } \rightarrow \\
\text { Independent } \\
\text { variable } \downarrow\end{array}$} & \multicolumn{8}{|c|}{ Knowledge sharing } \\
\hline & \multicolumn{4}{|c|}{ Sharing intention } & \multicolumn{4}{|c|}{ Sharing behavior } \\
\hline & \multicolumn{2}{|c|}{ Model I } & \multicolumn{2}{|c|}{ Model II } & \multicolumn{2}{|c|}{ Model I } & \multicolumn{2}{|c|}{ Model II } \\
\hline $\begin{array}{l}\text { Authentic } \\
\text { leadership }\end{array}$ & $\beta$ & $\rho$ & $\beta$ & $\rho$ & $\beta$ & $\rho$ & $\beta$ & $\rho$ \\
\hline Self-perception & $1.977 *$ & 0.013 & $1.836^{*}$ & 0.017 & & 0.000 & & 0.007 \\
\hline $\begin{array}{l}\text { Relation } \\
\text { transparency }\end{array}$ & & 0.006 & $1.927^{*}$ & 0.012 & & 0.000 & $1.896^{*}$ & 0.015 \\
\hline $\begin{array}{l}\text { Equalization } \\
\text { treatment }\end{array}$ & & 0.000 & $1.983^{*}$ & 0.008 & & 0.000 & & 0.000 \\
\hline $\begin{array}{l}\text { Internalization of } \\
\text { morality }\end{array}$ & & 0.000 & & 0.002 & & 0.000 & & 0.000 \\
\hline \multicolumn{9}{|l|}{$\begin{array}{l}\text { Psychological } \\
\text { capital }\end{array}$} \\
\hline Self-efficacy & & & & 0.006 & & & & 0.000 \\
\hline Hope & & & & 0.000 & & & & 0.006 \\
\hline Optimism & & & & 0.000 & & & & 0.000 \\
\hline Restoring force & & & & 0.007 & & & & 0.000 \\
\hline $\mathrm{F}$ & \multicolumn{2}{|c|}{23.842} & \multicolumn{2}{|c|}{27.671} & \multicolumn{2}{|c|}{32.934} & \multicolumn{2}{|c|}{35.276} \\
\hline $\mathrm{P}$ & \multicolumn{2}{|c|}{$0.000 * * *$} & \multicolumn{2}{|c|}{$0.000 * * *$} & \multicolumn{2}{|c|}{$0.000 * * *$} & \multicolumn{2}{|c|}{$0.000 * * *$} \\
\hline $\mathrm{R} 2$ & \multicolumn{2}{|c|}{0.159} & \multicolumn{2}{|c|}{0.243} & \multicolumn{2}{|c|}{0.237} & \multicolumn{2}{|c|}{0.251} \\
\hline Adjusted R2 & \multicolumn{2}{|c|}{0.023} & \multicolumn{2}{|c|}{0.029} & \multicolumn{2}{|c|}{0.034} & \multicolumn{2}{|c|}{0.037} \\
\hline
\end{tabular}

Note: * stands for $\mathrm{p}<0.05, * * *$ for $\mathrm{p}<0.001$.

\section{CONCLUSION}

With Regression Analysis, the relation between authentic leadership and psychological capital appears that authentic leadership presents positive effects on tacit psychological capital, conforming to H1 in this study. Such a result is similar to the past research, showing the actively positive psychology state as the definition of authentic leadership and the positive effects of psychology state of leaders in China Association for NGO Cooperation on psychological capital. Concerning the relations between psychological capital and knowledge sharing, the Regression Analysis result presents the positive effect of psychological capital on knowledge sharing, conforming to $\mathrm{H} 2$ in this study. The result is similar to the past research, showing that the positive psychological state of subordinates in China Association for NGO Cooperation would help the occurrence of knowledge sharing behavior. In this case, the employees in China Association for NGO Cooperation appearing positive emotion is similar to positive psychological state 
of self-confidence, hope, optimism, and restoring force in psychological capital which could affect knowledge sharing among employees and present beneficial knowledge sharing behavior to China Association for NGO Cooperation. With Regression Analysis of the relations among psychological capital, authentic leadership, and knowledge sharing, psychological capital shows partially mediating effects on the relation between authentic leadership and knowledge sharing that $\mathrm{H} 3$ and $\mathrm{H} 4$ are partially supported. Authentic leaders in China Association for NGO Cooperation would pay attention to active psychological ability, utilize the function and mechanism in the leadership process, and apply personal positive psychology to affect and encourage the subordinates' self-awareness and selfdevelopment. However, such effects do not completely influence knowledge sharing, but merely part of psychological state could affect knowledge sharing through functions. In this case, it could partially enhance knowledge sharing.

The effects of authentic leadership and psychological capital on knowledge sharing in China Association for NGO Cooperation show the importance of authentic leadership that the following suggestions are proposed in this study. 1. The psychological quality of leaders and the followers should be emphasized. Being a leader, China Association for NGO Cooperation should not focus on gaining power, fame, or money, but see through personal leadership to positively change the subordinates and promote China Association for NGO Cooperation to return to the society. 2 . Knowledge sharing behavior should be properly induced. When most members in China Association for NGO Cooperation receive the effectiveness from knowledge dissemination, each person's homogeneity is intangibly enhanced. In other words, it becomes more difficult to become a unique and exclusive person among numerous employees to replace others. 3. Recruitment and training of human resources. Research indicates that the stronger psychological capital would enhance knowledge sharing behavior. For this reason, China Association for NGO Cooperation should stress on cultivating the psychological capital of authentic leadership, consciously cultivate the self-efficacy, optimism, hope, and restoring force of leaders in China Association for NGO Cooperation through psychological capital training, and encourage leaders and employees in China Association for NGO Cooperation keeping optimistic attitudes and being full of hope to the life and job. 


\section{REFERENCES}

Avey, J.B., Luthans, F. and Youssef, C.M. (2010). The additive value of positive psychological capital in predicting work attitudes and behaviors. Journal of Management, 36(2), 430-452.

Deshpande, S.P., Joseph, J. and Shu, X. (2011). Ethical climate and managerial success in China. Journal of Business Ethics, 99(4), 527-534.

Fu, W. and Deshpande, S.P. (2012). Factors impacting ethical behavior in a Chinese state-owned steel company. Journal of Business Ethics, 105(2), 231-237.

Fu, W., Deshpande, S.P. and Zhao, X. (2011). The impact of ethical behavior and facets of job satisfaction on organizational commitment of Chinese employees. Journal of Business Ethics, 104(4), 537-543.

Gentry, W.A., Gilmore, D.C., Shuffler, M.L. and Leslie, J.B. (2012). Political skill as an indicator of promotability among multiple rater sources. Journal of Organizational Behavior, 33, 89-104.

Homburg, C., Müller, M. and Klarmann, M. (2011). When should the customer really be king? On the optimum level of salesperson customer orientation in sales encounters. Journal of Marketing, 75(2), 55-74.

Kalshoven, K., Den Hartog, D.N. and De Hoogh, A.H.B. (2011). Ethical leader behavior and big five factors of personality. Journal of Business Ethics, 100(1), 349-366.

Luthans, F., Avey, J.B., Avolio, B.J. and Peterson, S.J. (2010). The development and resulting performance impact of positive psychological capital. Human Resource Development Quarterly, 21(1), 41-67.

Mayer, D.M., Kuenzi, M. and Greenbaum, R.L. (2010). Examining the link between ethical leadership and employee misconduct: the mediating role of ethical climate. Journal of Business Ethics, 95, 9-16.

McMurray, A.J., Pirola-Merlo, A., Sarros, J.C. and Islam, M.M. (2010). Leadership, climate, psychological capital, commitment, and wellbeing in a non-profit organization. Leadership \& Organization Development Journal, 31(5), 436-457.

Reed, L.L., Vidaver-Cohen, D. and Colwell, S.R. (2011). A new scale to measure executive servant leadership: Development, analysis, and implications for research. Journal of Business Ethics, 101(3), 415-434.

Resick, C.J., Martin, G.S., Keating, M.A., Dickson, M.W., Kwan, H.K. and Peng, C. (2011). What ethical leadership means to me: Asian, American, and European perspectives. Journal of Business Ethics, 101(3), 435-457.

Walumbwa, F.O., Mayer, D.M., Wang, P., Wang, H., Workman, K. and Christensen, A.L. (2011). Linking ethical leadership to employee performance: The roles of leader-member exchange, self-efficacy, and organizational identification. Organizational Behavior and Human Decision Processes, 115(2), 204-213.

Walumbwa, F.O., Mayer, D., Wang, P., Wang, H. and Workman, K.M. (2010). Opening the black box: linking ethical leadership to employee performance. Academy of Management Meeting, Montreal, Canada.

Walumbwa, F.O., Peterson, S.J., Avolio, B.J. and Hartnell, C.A. (2010). An investigation of the relationships among leader and follower psychological capital, service climate, and job performance. Personnel Psychology, 63(4), 937-963.

Walumbwa, F.O., Wang, P., Wang, H., Schaubroeck, J. and Avolio, B.J. (2010). Psychological processes linking authentic leadership to follower behaviors. The Leadership Quarterly, 21(5), 901-914. 
Yildirm, A. and Bastug, I. (2010). Teachers' views about ethical leadership behaviors of primary school directors. Procedia - Social and Behavioral Sciences, 2(2), 4109-4114.

Yilmaz, E. (2010). The analysis of organizational creativity in schools regarding principals' ethical leadership characteristics. Procedia - Social and Behavioral Sciences, 2(2), 3949-3953.

Yukl, G. (2010). Leadership in Organizations. Upper Saddle River, N.J.: Pearson/Prentice Hall. 